\title{
EFFECT OF ESTERIFICATION ON MOISTURE ABSORPTION OF SINGLE ARECA FIBER
}

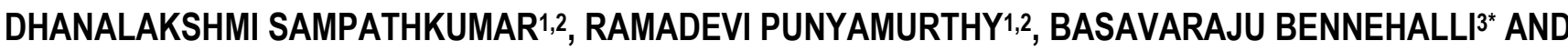 SRINIVASA CHIKKOL VENKATESHAPPA 4}

\author{
${ }^{1}$ Research Scholar, Jawaharlal Nehru Technological University, Hyderabad-500 085, Andhra Pradesh, India. \\ 2Department of Chemistry, KLE Society's BVB College of Engineering \& Technology, Hubli-580 031, Karnataka, India. \\ 3Department of Chemistry, Alva's Institute of Engineering \& Technology, Moodbidri-574 225, Karnataka, India. \\ ${ }^{4}$ Department of Mechanical Engineering, GM Institute of Technology, Davangere-577 006, Karnataka, India. \\ *Corresponding Author: Email-basavaraju_b@yahoo.co.in
}

Received: May 14, 2012; Accepted: May 24, 2012

\begin{abstract}
Environmentally beneficial composites can be made by replacing synthetic fibers with various types of cellulose fibers. The most important factor in finding good fiber reinforcement in the composite is the strength of adhesion between matrix polymer and fiber. Due to the presence of hydroxide and other polar groups in various constituents of natural fiber, the moisture absorption is high which leads to poor wettability and weak interfacial bonding between fibers and the more hydrophobic matrices. Therefore, it is necessary to impart hydrophobic nature to the natural fibers by suitable chemical treatments in order to develop composites with better mechanical properties. In the present work, the effect of esterification on the moisture absorption property of single areca fiber has been investigated.
\end{abstract}

Key words- natural fiber, moisture Absorption, chemical treatment, areca fiber, acrylic acid, sea water.

Citation: Dhanalakshmi Sampathkumar, et al. (2012) Effect of Esterification on Moisture Absorption of Single Areca Fiber. International Journal of Agriculture Sciences, ISSN: 0975-3710 \& E-ISSN: 0975-9107, Volume 4, Issue 4, pp-227-229.

Copyright: Copyright@2012 Dhanalakshmi Sampathkumar, et al. This is an open-access article distributed under the terms of the Creative Commons Attribution License, which permits unrestricted use, distribution, and reproduction in any medium, provided the original author and source are credited.

\section{Introduction}

Agro-based resources, also referred to as lignocellulosics, are resources that contain cellulose, hemicelluloses, and lignin. Lignocellulosics include wood, agricultural residues, water plants, grasses, and other plant substances. Fiber technology, high performance adhesives, and fiber surface modification utilized natural fibers in the fabrication of structural lignocellulosic composites and reported that these natural fibers-reinforced composites possess better chemical resistance, electrical resistance, good thermal and acoustic insulating properties, and high resistance to fracture. This has stimulated the use of hard natural cellulose fibers as an attractive alternative to synthetic fibers because of their low cost, less weight, and density.

High moisture absorption, poor wettability, and poor fiber-matrix adhesion are the major drawbacks of natural fiber reinforced composite materials. A better adhesion between hydrophilic fiber and hydrophobic matrix, and enhanced mechanical properties of natural fiber reinforced composite materials can be achieved by suitable chemical modification of natural fiber. In the case of lignocellu- losics, cell wall polymers, extractives, and inorganics are the components that, if modified, would change the properties of the resources.

There are several ways such as acetylation, methylation, benzoylation, permanganate treatment, acrylation etc to chemically modify the lignocellulosic cell wall polymers. The most abundant single site for reactivity in these polymers is the hydroxyl group and most reaction schemes have been based on the reaction of hydroxyl groups. The hygroscopicity of the lignocellulosic material can be reduced by replacing some of the hydroxyl groups on the cell wall polymers with bonded chemical groups [1]. Acrylation is one such method for reducing the hygroscopicity of the natural fiber. The polymer hydroxyl group of the cell wall reacts with carboxylic group of acrylic acid to yield an ester so that fiber becomes more hydrophobic in nature.

Many attempts have been made to study the properties of chemically treated natural fiber-reinforced polymer composites. Vilay et al. investigated the effect of acrylation in bagasse fiber reinforced unsaturated polyester composites and reported that storage mod- 
ulus and glass transition temperature of composites found to improve, and water absorption of composites found to decrease compared to untreated bagasse fiber composites [2].

Jannah et al. studied the effect of acrylation in woven banana reinforced unsaturated polyester composites and they showed, treated composite systems show improvements in flexural properties. Furthermore, they reported that the treated fiber composites reduce the water absorption compared to the untreated composite system [3].

Only a few studies on the mechanical properties of acrylic acid treated natural fiber-reinforced composite materials were reported and there is no information on the water absorption studies of acrylated single natural fiber. A better understanding of moisture absorption property of fibers will help to develop a productive use of fibers in composite materials. Therefore, this study seeks to determine the moisture absorption characteristic of acrylic acid treated single areca fiber.

Areca belongs to the species Areca catechu Linnaeus under the family palmecea [4]. The areca empty fruit fiber is composed of 35 $-65 \%$ hemicellulose, $13-26 \%$ lignin, pectin, and protopectin [5]. The average filament length of the areca fiber is $4 \mathrm{~cm}$. At present, a small quantity of areca empty fruit material is being used as a fuel in areca nut processing and plenty of unused husk which is left in the plantation causes bad odour and other decay-related problems [6].

Few researchers have studied the areca fiber-reinforced composites and found to have a good flexural strength and adhesion tensile properties. Also, reported that areca composites would be very promising material for packing and other general structural applications with a moderate duration as they shown excellent resistance moisture to absorption when compared to wood based particle boards [7-10].

Areca fiber can also be used for making value added items like thick boards, fluffy cushions, non-woven fabrics, thermal insulators, etc. [11]. Thus, the use of unmanaged areca husk as a structural material requires a detailed study of physical, chemical and thermal characteristics. One of the most important issues is the degradation behaviour of the composites exposed to environmental conditions such as humidity, sunlight or microorganisms. Also, the poor resistance of the fibers to water absorption can have undesirable effects on the mechanical properties and the dimensional stability of the composites. Therefore, it is important to study in detail the water absorption behaviour in order to estimate not only the consequences that the water absorbed may have, but also the durability of natural fibers composites aged under water.

\section{Materials and Methods \\ Materials}

Areca empty fruit fibers (husk) were obtained from Madhu Farm House, Nilogal, Davangere, Karnataka, India. Analytical grade reagents were purchased from Qualigens Company and used as received.

\section{Fiber extraction}

Selected areca fruit husks were used to study. Dried areca husk was soaked in deionised water for about five days. The soaking process loosens the fibers and can be extracted out easily. Finally, the fibers were washed again with deionised water and dried at room temperature for about 15 days. The dried fibers are designated as untreated fibers.

\section{Alkali treatment}

The fibers are first dewaxed by soaking in 1:2 mixtures of ethanol and benzene for $72 \mathrm{~h}$, followed by washing with deionised water and then air dried. The dewaxed fibers were immersed in $20 \%$ $\mathrm{NaOH}$ solution, where the total volume of the solution was 15 times the weight of the fibers. The fibers were kept in alkaline solution for $72 \mathrm{~h}$ at room temperature; they were thoroughly washed in running water and then neutralized with $2 \%$ acetic acid solution. Lastly, the fibers were washed again in running water to remove the last traces of acid sticking to it, so that the $\mathrm{pH}$ of the fibers was approximately 7 . Then, they were dried at room temperature for $48 \mathrm{~h}$ to obtain alkali-treated fibers.

\section{Acrylic acid treatment}

Alkali treated areca fiber was soaked in $5 \%$ acrylic acid (AA) solution at $50{ }^{\circ} \mathrm{C}$ for $1 \mathrm{~h}$, then washing with distilled water thoroughly and dried in an oven for $24 \mathrm{~h}$ at the temperature of $70{ }^{\circ} \mathrm{C}$ [12].

\section{Water absorption studies}

Water absorption studies on untreated and treated fibers were carried out in various sources of water such as Pond water, River water, Bore water, and Sea water. The $\mathrm{pH}$ values of water samples were; Bore water: 7.40, Pond water: 8.20, River water: 7.74, and Sea water: 7.76. A bundle of fibers $(2 \mathrm{~g})$ was immersed in beakers containing various sources of water. After $24 \mathrm{~h}$, the fiber bundle is taken out from the beakers and fibers were squeezed and dried in between the folds of filter paper. Finally the weight of the fibers was taken and the percentage of water absorption is calculated as follows:

$$
\% \text { of Water Absorption } \frac{\text { Difference in Weight }}{\text { Initial Weight }} \times 100
$$

Then again the sample was soaked in water, and the same process was repeated after every $24 \mathrm{~h}$ for $2400 \mathrm{~h}$. A graph is plotted between $\%$ water absorption and square root of time.

\section{Results and Discussion}

Lignocellulosics are three-dimensional, polymeric composites made up primarily of cellulose, hemicellulose and lignin. In natural fibers, semicrystalline cellulose is the main reinforcement material. The cellulose is held together by amorphous hemicelluloses and fibers are cemented together in the plant by lignin which is commonly known as plant cell adhesive. Lignocellulosic fibers may differ in chemical composition, but have very similar properties such as flammability, thermoplasticity, moisture Absorption, and degradation by acids, bases and ultraviolet radiation. All of these characteristics will result in the specific end use of lignocellulosics in composite formulation [13].

Lignocellulosics change dimensions with changing moisture content because the cell wall polymers contain hydroxyl and other oxygen containing groups that attract moisture through hydrogen bonding. The hemicellulose is mainly responsible for moisture Absorption, but the accessible cellulose, noncrystalline cellulose, lignin and surface of crystalline cellulose also play major roles. 
Moisture swells the cell wall, and the fiber expands until the cell wall is saturated with water (fiber saturation point). Beyond this saturation point, moisture exists as free water in the void structure and does not contribute further expansion [14].

To measure the water absorption of the areca fiber, the fiber was immersed in a beaker containing various sources of water at room temperature. After every 24 hours, the fiber was taken out and excess water on the fiber surface was removed before weighing. Three replicates were tested and the results were presented as average of three.

The Comparison of moisture absorption of untreated areca fiber in various water samples showed that areca fiber absorbs more moisture in bore water and less in sea water. Also, surface treated fiber absorbs less moisture than the untreated fiber in all water samples. Further, from Figure 1, comparison of moisture absorption property of untreated, alkali treated, and acrylic acid treated areca fiber in sea water, it can be observed that the acrylic acid treated fiber absorbs less moisture than the alkali treated fiber. This is due to the change in the surface topography of the fibers due to alkali and acrylic acid treatments.

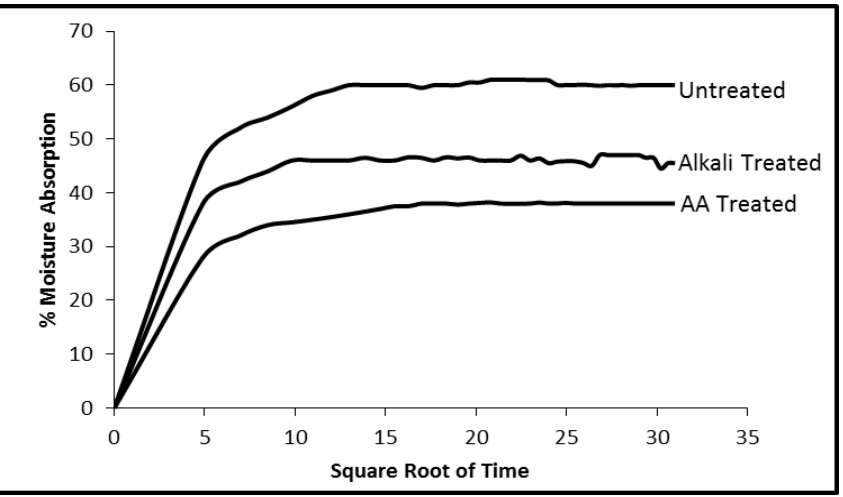

Fig. 1- Comparison of moisture absorption property of untreated, alkali treated, and acrylic acid treated areca fiber in sea water

In untreated fibers, fibrils are bound together by hemicellulose and lignin. The chemical treatments had removed most of the hemicellulose and lignin and thus areca fiber become more hydrophobic [3]. Also, in all natural cellulose fibers, a hollow cavity called lumen exists in the unit cell of the fibers [14]. The hollow cavity generates more pathways for water to start diffusing into the fiber. The velocity of the diffusion process can be reduced by reducing the void content of the fiber. The cellular structure of the fiber destroys by the chemical treatment; hence reduced the void content and this in turn reduced the moisture uptake of treated fiber.

\section{Conclusion}

The potential of using natural fibers as reinforcing agents is based on the interfacial properties between fiber and polymer matrix. Also, the poor resistance of the fibers to water absorption can have undesirable effects on the structure, dimensional and mechanical properties of the natural fiber reinforced composites. It is possible to reduce the moisture absorption property of areca fiber through its surface modification. The results presented in this work indicate that the areca fiber treated with acrylic acid absorbs less moisture than the untreated, alkali treted fiber.

\section{Acknowledgement}

The authors would like to thank Madhu Farm House, Nilogal for providing a good quality areca fruit husk. The first author would like to thank the Management of KLE Society's BVB College of Engineering and Technology, Hubli, Karnataka, India for the kind encouragement and constant support provided. She sincerely thanks Prof. Ashok Shettar, Principal, KLE Society's BVB College of Engineering and Technology, without his encouragement and motivation, this work would not have been possible. The second author would like to thank Dr. M. Mohan Alva, Chairman, Alva's Education Foundation, Moodbidri and Dr. M. Govinde Gowda, Principal, Alva's Institute of Engineering \& Technology, Moodbidri, Karnataka, India, for their kind encouragement and support provided. The third author would like to thank Sri G. M. Lingaraju, Secretary, GM Institute of Technology, Davangere, India, for their encouragement and support throughout this work.

\section{References}

[1] Roger M.R. (1998) Science and Technology of Polymers and Advanced Materials. New York. 717-732

[2] Vilay M., Mariatti R., Mat T. and Mitsugu T. (2008) Composites Science and Technology, 68, 631-638.

[3] Jannah M., Mariatti M., Bakkar A. and Khalil A. (2009) Journal of Reinforced Plastics and Composites, 28(12), 1519-1532.

[4] Rajan A. and Kurup J.G. (2005) Biochemical Engineering Journal, 25, 237-242.

[5] Ramachandra T.V., Kamakshi G. and Shruthi B.V. (2004) Renew. Sust. Energy. Rev. 8, 1-47.

[6] Ghosh S.K., Sinha M.K. and Bandopadhya S.K. (1975) J. Plant Crops, 3, 29-33.

[7] Swamy R.P., Mohankumar G.C., Vrushabhendrappa Y. And Joseph V. (2004) Journal of Reinforced Plastics and Composites, 23(13), 1373-1382.

[8] Srinivasa C.V., Arifulla A., Goutham N., Santhosh T., Jaeethendra H.J., Ravikumar R.B. and Anil S.G. (2011) Materials and Design, 32(4), 2469-2475.

[9] Srinivasa C.V., Suresh Y.J. and Premakumar W.P. (2011) Advances in Polymer Technology, DOI 10.1002/adv.20255).

[10]Srinivasa C.V., Basavaraju B., Mownesh G.K. and Raghupatel G.R. (2010) BioResources, 5(3), 1845-1858.

[11]Mohankumar G.C. (2008) World Congress on Engineering, II, WCE 2008, London, U.K.

[12]Panigrahi S., Li X. and Tabil L. (2008) International Conference on Flax and Other Bast Plants, ID number: 83 (ISBN: 978-0-9809664-0-4), 399-407.

[13]Aziz S.H. and Ansell M.P. (2004) Science and Technology, 64, 1219-1230.

[14]Reddy N. and Yang Y. (2005) Trend Biotechnol, 23(1), 22-27. 